\title{
Preparation and ferroelectric properties of barium-ion-doped strontium bismuth tantalate thin films
}

\author{
Chung-Hsin Lu*, Da-Pong Chang \\ Department of Chemical Engineering, National Taiwan University, Taipei, Taiwan, ROC
}

\begin{abstract}
$\left(\mathrm{Sr}_{0.5} \mathrm{Ba}_{0.5}\right)_{x} \mathrm{Bi}_{y} \mathrm{Ta}_{2} \mathrm{O}_{z}$ (SBBT) films were prepared on $\mathrm{Pt} / \mathrm{Ti} / \mathrm{SiO}_{2} / \mathrm{Si}$ substrates by a metal-organic decomposition method. At low temperatures, the phase transformation of films from fluorite-type structure to SBBT structure was suppressed with increasing the amounts of bismuth ions. As temperature increased, the phase transformation was improved by excess bismuth ions. Adding excess bismuth ions also resulted in an increase in the grain size of the prepared films. The value of the remanent polarization of thin film was also increased by adding excess bismuth contents. It was found that the ferroelectric characteristics of these films were significantly affected by the composition in the films.
\end{abstract}

(C) 2007 Elsevier Ltd. All rights reserved.

Keywords: A. Thin films; B. Chemical synthesis; D. Microstructure

\section{Introduction}

Recently, the layered-structure perovskites have attracted considerable attention for their applications of low-voltage and high-speed nonvolatile random access memory (NvRAM). The chemical formula of these layered-structure compounds is $\left(\mathrm{Bi}_{2} \mathrm{O}_{2}\right)^{2+}\left(\mathrm{A}_{x-1} \mathrm{~B}_{x}\right.$ $\left.\mathrm{O}_{3 x-1}\right)^{2-}$, where $\mathrm{A}$ and $\mathrm{B}$ indicates cations, and $x$ represents numbers of perovskite layers between two $\left(\mathrm{Bi}_{2} \mathrm{O}_{2}\right)^{2+}$ layers. These materials were synthesized by Aurivillus in 1949 and hence were named as Aurivillus compounds. Comparing with $\mathrm{Pb}(\mathrm{Zr}, \mathrm{Ti}) \mathrm{O}_{3}$-based materials, thin films of the Aurivillus compounds with $x=2$, such as $\mathrm{SrBi}_{2} \mathrm{Ta}_{2} \mathrm{O}_{9}, \mathrm{BaBi}_{2} \mathrm{Ta}_{2} \mathrm{O}_{9}$, and $\mathrm{SrBi}_{2} \mathrm{Nb}_{2} \mathrm{O}_{9}$, exhibit several advantages. The excellent properties of low leakage current, long retention time, fatigue-free, and stable imprint characteristics improve the applications in FeRAM [1-11]. The processes for preparing $\mathrm{SrBi}_{2} \mathrm{Ta}_{2} \mathrm{O}_{9}$-based thin films on Si-based substrates have been widely examined.

Strontium bismuth tantalite $\left(\mathrm{SrBi}_{2} \mathrm{Ta}_{2} \mathrm{O}_{9}, \mathrm{SBT}\right)$ is one of the promising materials of Aurivillus compounds with

\footnotetext{
*Corresponding author.

E-mail address: chlu@ntu.edu.tw (C.-H. Lu).
}

excellent ferroelectric properties of long fatigue endurance and large remanent polarization $\left(P_{\mathrm{r}}\right)$ [12-16]. The previous studies have revealed that the layered-structured perovskites exhibit the characteristics of low leakage current, low operating voltage, stable imprinted characteristics, and high polarization retention up to long switching cycles. Because of the slight difference of cation radii between $\mathrm{Sr}^{2+}$ and $\mathrm{Ba}^{2+}$, the formation of solid solutions of these compounds is feasible. In present study, barium ions were doped into $\mathrm{SrBi}_{2} \mathrm{Ta}_{2} \mathrm{O}_{9}$ films to form solid solutions. $\left(\mathrm{Sr}_{0.5} \mathrm{Ba}_{0.5}\right) \mathrm{Bi}_{y} \mathrm{Ta}_{2} \mathrm{O}_{z}$ thin films were prepared via a metalorganic decomposition (MOD) method on $\mathrm{Pt} / \mathrm{Ti} / \mathrm{SiO}_{2} / \mathrm{Si}$ substrates. Varying the stoichiometry of bismuth ions, the formation of the layered-structure perovskites, crystallinity, and the ferroelectric properties were investigated in this study.

\section{Experimental}

Strontium 2-ethylhexanoate $\left[\mathrm{Sr}\left(\mathrm{C}_{8} \mathrm{H}_{15} \mathrm{O}_{2}\right)_{2}\right]$, barium 2ethylhexanoate $\left[\mathrm{Ba}\left(\mathrm{C}_{8} \mathrm{H}_{15} \mathrm{O}_{2}\right)_{2}\right]$, bismuth 2-ethylhexanoate $\left[\mathrm{Bi}\left(\mathrm{C}_{8} \mathrm{H}_{15} \mathrm{O}_{2}\right)_{2}\right]$, and tantalate ethoxide $\left[\mathrm{Ta}\left(\mathrm{OC}_{2} \mathrm{H}_{5}\right)_{5}\right]$ were used as the starting materials. MOD was employed to fabricate $\left(\mathrm{Sr}_{0.5} \mathrm{Ba}_{0.5}\right)_{x} \mathrm{Bi}_{y} \mathrm{Ta}_{2} \mathrm{O}_{z}$ (SBBT) thin films. The starting materials were mixed in toluene and then were 
spin-coated onto $\mathrm{Pt} / \mathrm{Ti} / \mathrm{SiO}_{2} / \mathrm{Si}$ substrates. The as-deposited films were baked on the hot plate at $150^{\circ} \mathrm{C}$. After the solvent was removed, the films were pyrolyzed at $400{ }^{\circ} \mathrm{C}$ to burn out the remaining organics. The pyrolyzed films were annealed at $580-800^{\circ} \mathrm{C}$ for $1 \mathrm{~h}$ with oxygen flow to enhance

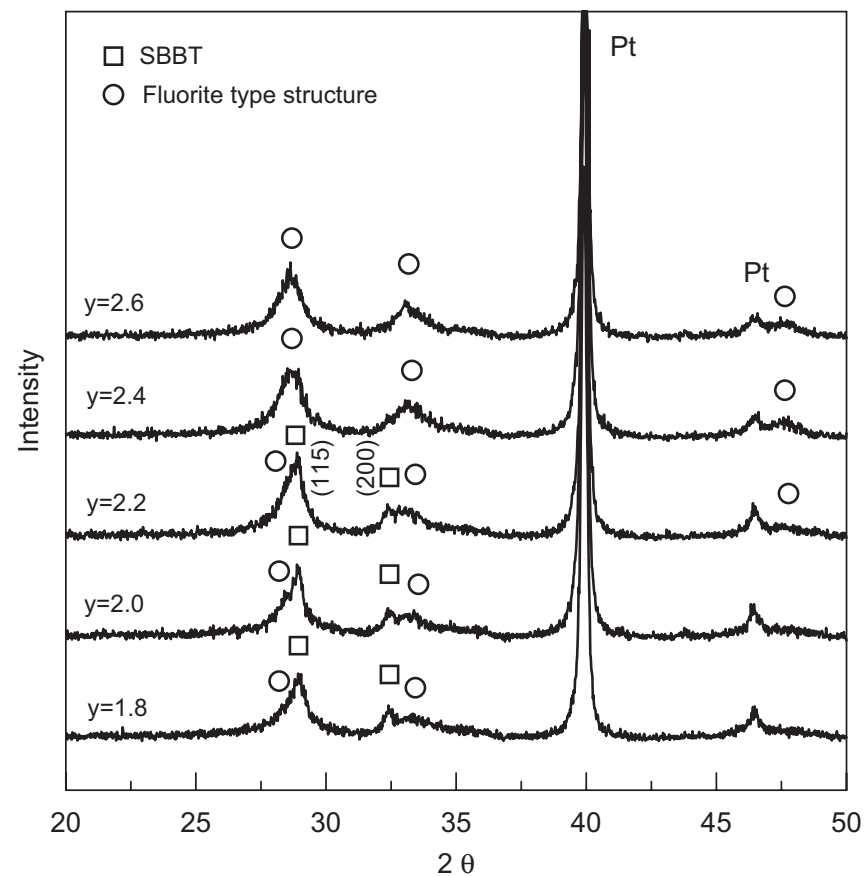

Fig. 1. XRD patterns of $\left(\mathrm{Sr}_{0.5} \mathrm{Ba}_{0.5}\right) \mathrm{Bi}_{y} \mathrm{Ta}_{2} \mathrm{O}_{z}$ thin films with different $y$ values annealed at $630^{\circ} \mathrm{C}$ for $1 \mathrm{~h}$.

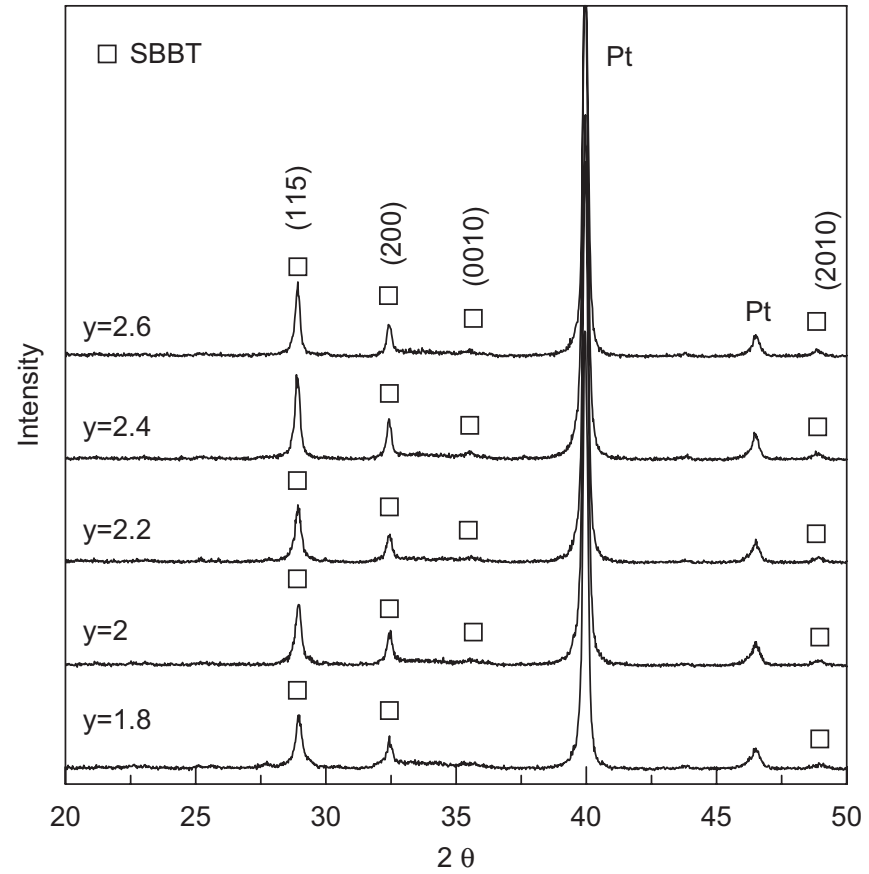

Fig. 2. XRD patterns of $\left(\mathrm{Sr}_{0.5} \mathrm{Ba}_{0.5}\right) \mathrm{Bi}_{y} \mathrm{Ta}_{2} \mathrm{O}_{z}$ thin films with different $y$ values annealed at $730^{\circ} \mathrm{C}$ for $1 \mathrm{~h}$. the crystallinity. The crystallite phases were identified by $\mathrm{X}$-ray diffraction (XRD) at room temperature using a MAC Science MXP3 XRD system with $\mathrm{Cu} \mathrm{K}_{\alpha}$ radiation at

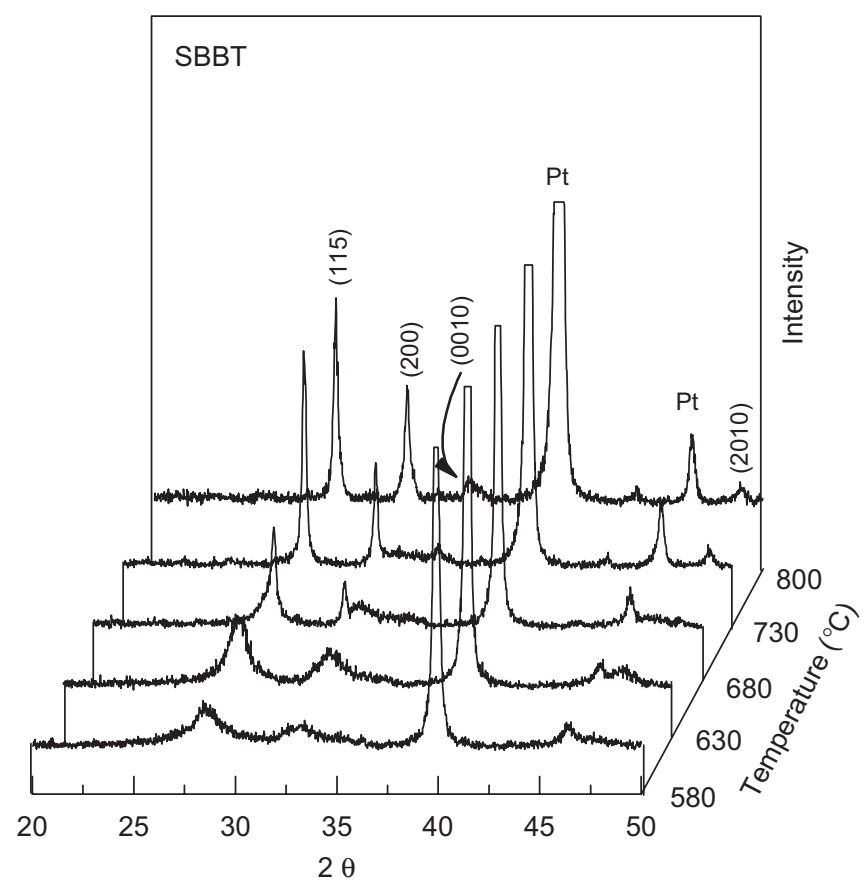

Fig. 3. XRD patterns of $\left(\mathrm{Sr}_{0.5} \mathrm{Ba}_{0.5}\right) \mathrm{Bi}_{2.4} \mathrm{Ta}_{2} \mathrm{O}_{z}$ thin films heated at (a) $580^{\circ} \mathrm{C}$, (b) $630^{\circ} \mathrm{C}$, (c) $680^{\circ} \mathrm{C}$, (d) $730^{\circ} \mathrm{C}$, and (e) $800^{\circ} \mathrm{C}$.

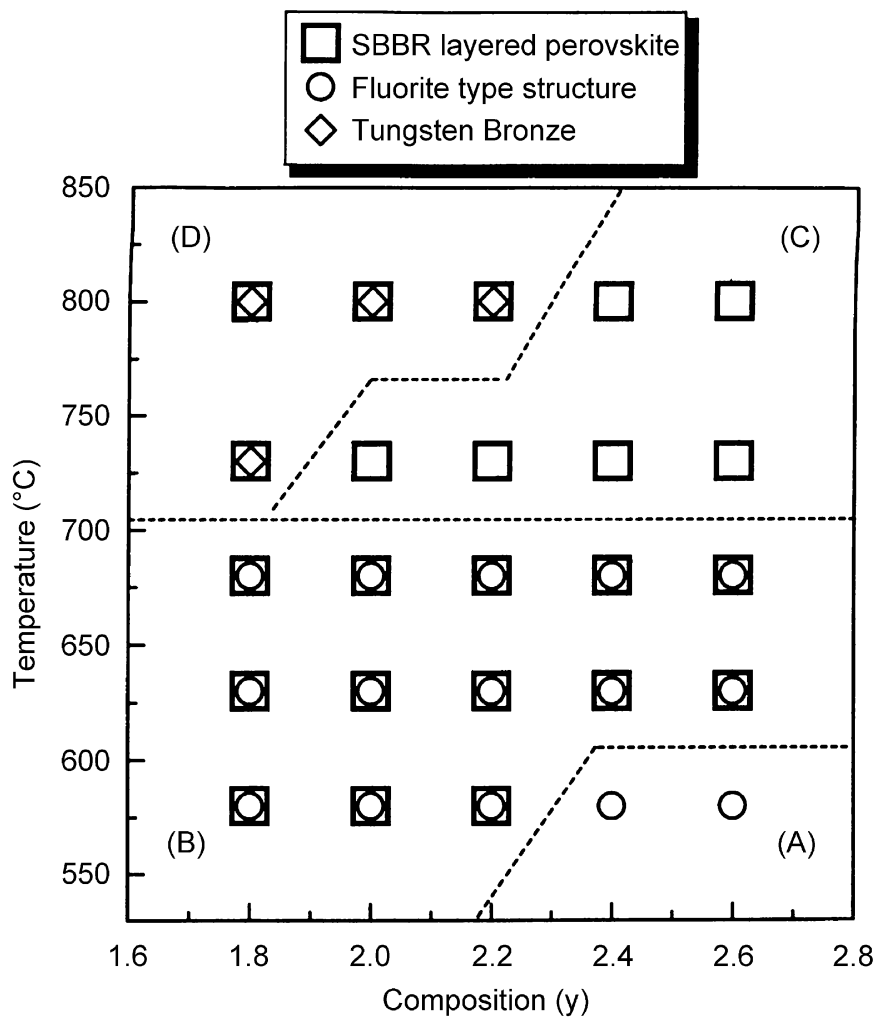

Fig. 4. Phase diagram of formation of $\left(\mathrm{Sr}_{0.5} \mathrm{Ba}_{0.5}\right) \mathrm{Bi}_{y} \mathrm{Ta}_{2} \mathrm{O}_{z}$ thin films. 
$40 \mathrm{kV}$ and $30 \mathrm{~mA}$. The surface morphologies and structure were examined by scanning electron microscopy (Hitachi model S- 800 microscope, $20 \mathrm{kV}$ ) and atomic force microscopy using tapping mode with amplitude modulation (Nanoscope IIIa, Digital Instruments Company, Santababara). The ferroelectric hysteresis measurements were conducted on films in metal-ferroelectric-metal configuration using a standardized ferroelectricity test system in the virtual ground.

\section{Results and discussion}

\subsection{Formation of $\left(\mathrm{Sr}_{0.5} \mathrm{Ba}_{0.5}\right) \mathrm{Bi}_{y} \mathrm{Ta}_{2} \mathrm{O}_{z}$ thin films}

Fig. 1 shows the XRD patterns of $\left(\mathrm{Sr}_{0.5} \mathrm{Ba}_{0.5}\right) \mathrm{Bi}_{y} \mathrm{Ta}_{2} \mathrm{O}_{z}$ thin films with different $y$ values annealed at $630^{\circ} \mathrm{C}$. At $y=1.8-2.2$, two structures, layered-structure perovskites (SBBT structure) and fluorite-type structure, are observed. With an increase in $y$, only fluorite-type structure is

b
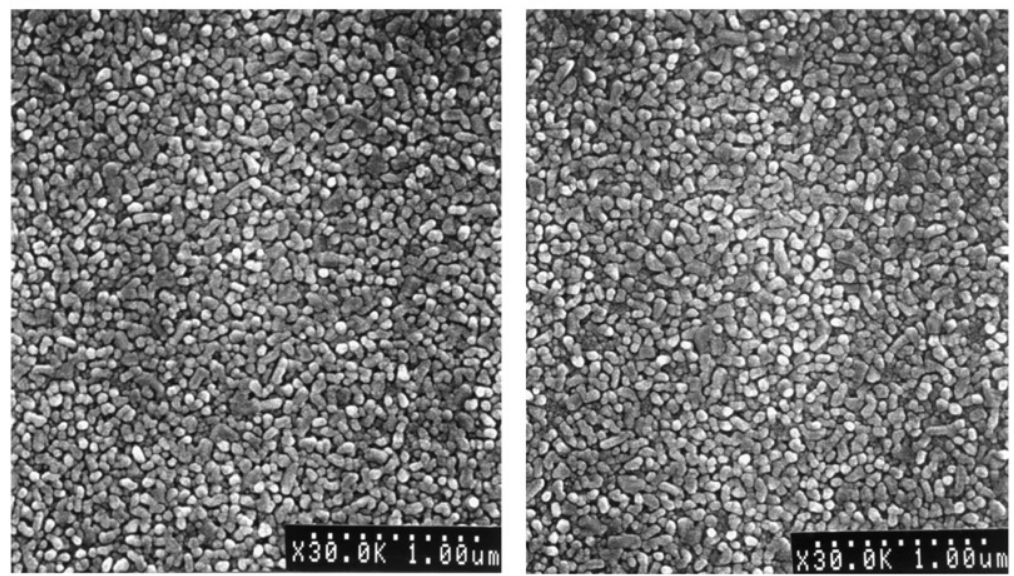

C

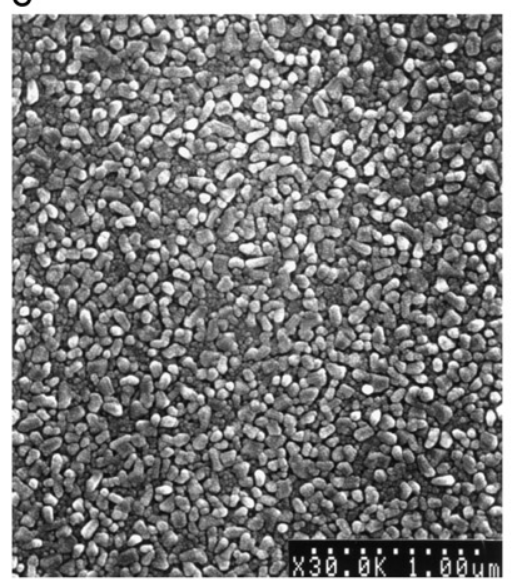

d

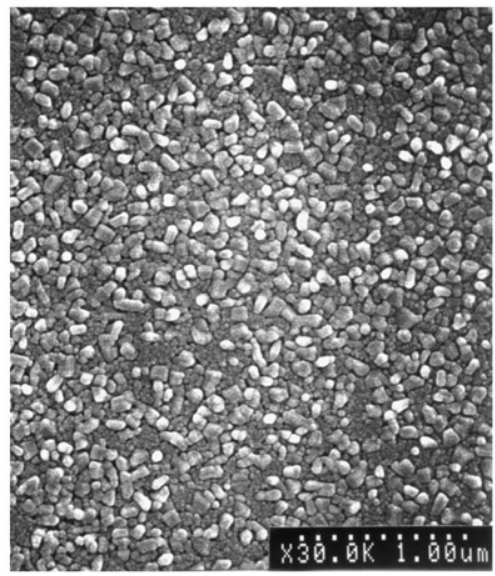

e

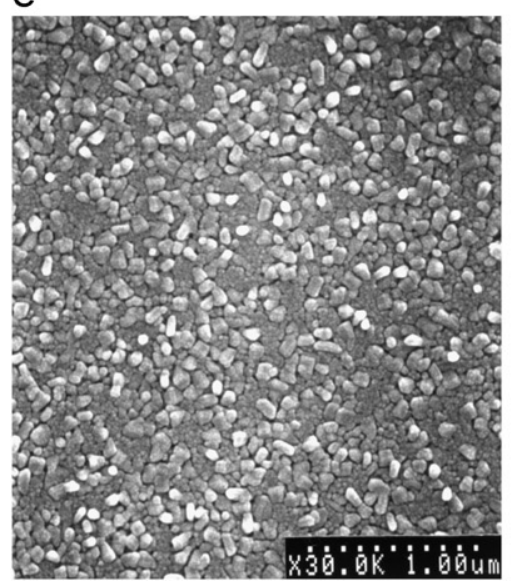

Fig. 5. Microstructures of $\left(\mathrm{Sr}_{0.5} \mathrm{Ba}_{0.5}\right) \mathrm{Bi}_{y} \mathrm{Ta}_{2} \mathrm{O}_{z}$ thin films annealed at $730{ }^{\circ} \mathrm{C}$ : (a) $y=1.8$, (b) $y=2.0$, (c) $y=2.2$, (d) $y=2.4$, and (e) $y=2.6$. 
obtained, and the SBBT structure disappears. When the films are annealed at $630^{\circ} \mathrm{C}$, SBBT structure and fluoritetype structure coexist regardless of variations in $y$. Fig. 2 illustrates the XRD patterns of $\left(\mathrm{Sr}_{0.5} \mathrm{Ba}_{0.5}\right) \mathrm{Bi}_{y} \mathrm{Ta}_{2} \mathrm{O}_{z}$ thin films with different $y$ values annealed at $730^{\circ} \mathrm{C}$. As the annealing temperature increases to $730^{\circ} \mathrm{C}$, the SBBT structure becomes the dominant phase for $y=2-2.6$. For $y=1.8$, a minor tungsten bronze type coexists with the perovskite structure. It is observed that there is a phase transformation from fluorite-type structure to SBBT structure with increasing temperature. In addition, it is also found that increasing the bismuth contents can enhance the crystallinity of the films.

Fig. 3 illustrates the XRD patterns of the films at $y=0.4$ heated at various temperatures. At $580^{\circ} \mathrm{C}$, only the fluorite structure exists. After heating at $630^{\circ} \mathrm{C}$, the crystallinity of the fluorite structure increases. The layered structure starts to form from $680^{\circ} \mathrm{C}$; however, a small amount of fluorite phase still remains. After heating at $730^{\circ} \mathrm{C}$, pure layered structure is completely formed.

Fig. 4 illustrates the phase diagram of SBBT. At $580^{\circ} \mathrm{C}$, the coexistence of SBBT structure and fluorite-type structure at $y=1.8-2.2$ indicates that the phase transformation takes place with less bismuth-ion doped at low temperatures. The phase transformation of fluorite type to SBBT structure is suppressed when excess bismuth-ion is doped. When temperature arises, this transformation is facilitated by excess bismuth-ion. Therefore, the fluoritetype structure has transferred to SBBT structure completely above $730^{\circ} \mathrm{C}$. However, the thin films decompose at high temperature, and tungsten bronze-type oxide is formed.

In order to examine the effects of bismuth contents on the preferred orientation of the prepared films, the degree of orientation is defined as follows:

$D_{(200)}=\frac{\left[I_{(200)} / I_{(115)}\right]_{\text {Film }}}{\left[I_{(200)} / I_{(115)}\right]_{\text {Powder }}}-1$,

where $I_{200}$ and $I_{115}$ are the diffraction intensity of the (200) and (1 15$)$ planes, respectively. It is found that when the value of $y$ increases from 1.8 to 2.6 , the degree of orientation in $a$-axis significantly decreases. It reveals that adding excess bismuth-ion suppresses the preferred orientation in $a$-axis.

\subsection{Microstructures and ferroelectric properties of $\left(\mathrm{Sr}_{0.5} \mathrm{Ba}_{0.5}\right) \mathrm{Bi}_{y} \mathrm{Ta}_{2} \mathrm{O}_{z}$ thin films}

The scanning electron micrographs of $\left(\mathrm{Sr}_{0.5} \mathrm{Ba}_{0.5}\right) \mathrm{Bi}_{y-}$ $\mathrm{Ta}_{2} \mathrm{O}_{z}$ thin films heated at $730^{\circ} \mathrm{C}$ are shown in Fig. 5. When $y=1.8$, the grain size of the films is around $90 \mathrm{~nm}$. When $y$ increases to 2.6, the grain size of the films also increases to around $200 \mathrm{~nm}$. This indicates that increasing the bismuth contents results in an increase in the grain size of the films. The ferroelectric characteristics of the prepared films heated at $730^{\circ} \mathrm{C}$ are analyzed by the hysteresis measurement. The obtained data are illustrated

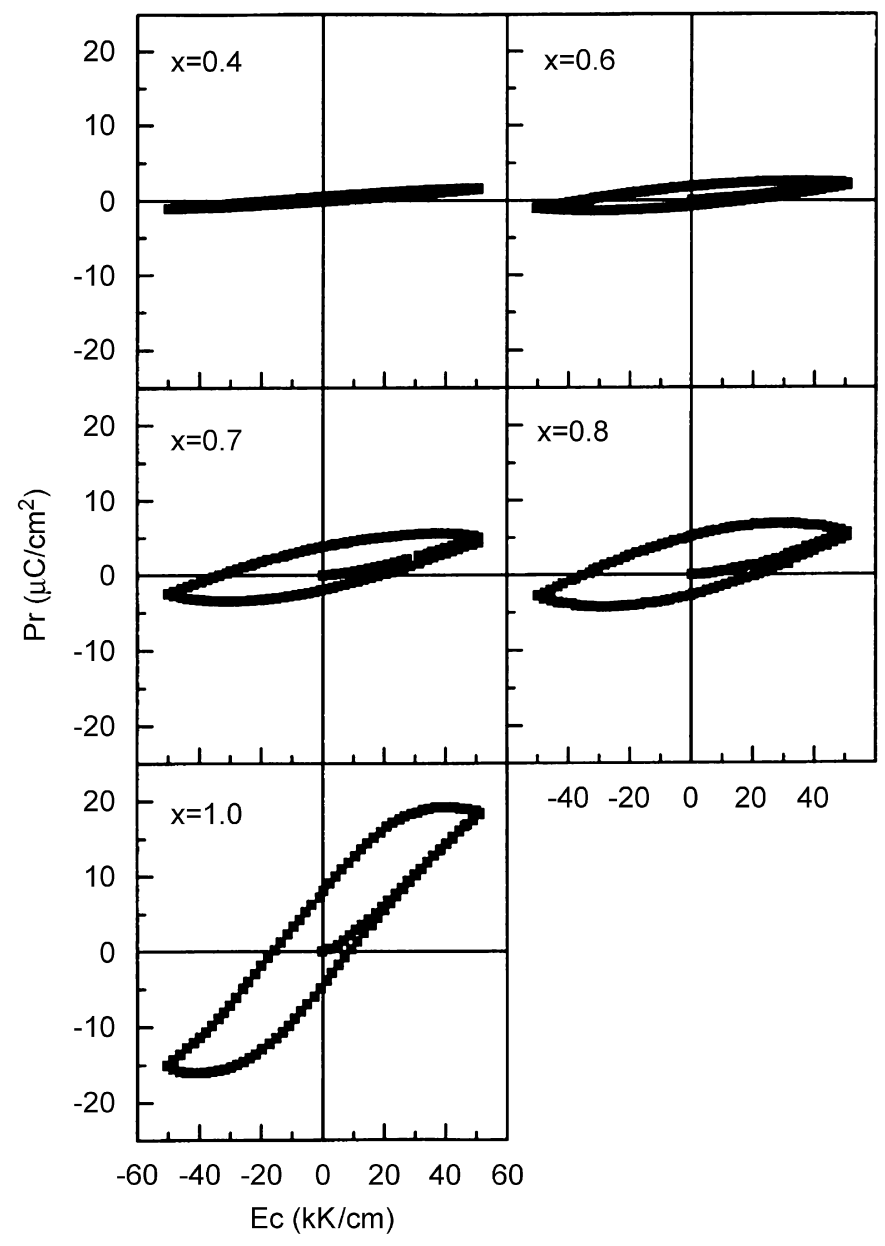

Fig. 6. Ferroelectric characteristics of $\left(\mathrm{Sr}_{0.5} \mathrm{Ba}_{0.5}\right)_{x} \mathrm{Bi}_{2.4} \mathrm{Ta}_{2} \mathrm{O}_{z}$ films annealed at $730^{\circ} \mathrm{C}$ for $1 \mathrm{~h}$.

in Fig. 6. When the value of $y$ is small, the values of $2 P_{\mathrm{r}}$ and $2 E_{\mathrm{c}}$ of thin films are also small. Increasing the contents of bismuth ions, the values of $2 P_{\mathrm{r}}$ and $2 E_{\mathrm{c}}$ gradually increases. When $y$ is equal to 2.4 , the values of $2 P_{\mathrm{r}}$ and $2 E_{\mathrm{c}}$ of thin films becomes $12.459 \mu \mathrm{C} / \mathrm{cm}^{2}$ and $28.44 \mathrm{kV} / \mathrm{cm}$, respectively. After $10^{10}$ switching cycles, these films exhibit good anti-fatigue properties. The value of $2 P_{\mathrm{r}}$ only slightly decreases $3.55 \%$. The above results reveals that $\left(\mathrm{Sr}_{0.5} \mathrm{Ba}_{0.5}\right) \mathrm{Bi}_{y} \mathrm{Ta}_{2} \mathrm{O}_{z}$ with good ferroelectric films are successfully prepared in this study.

\section{Conclusions}

$\left(\mathrm{Sr}_{0.5} \mathrm{Ba}_{0.5}\right)_{x} \mathrm{Bi}_{y} \mathrm{Ta}_{2} \mathrm{O}_{z}$ films were synthesized on $\mathrm{Pt} / \mathrm{Ti} /$ $\mathrm{SiO}_{2} / \mathrm{Si}$ substrates by a metal-organic decomposition method with different contents of strontium, barium, and bismuth ions. At low temperature, the phase transformation of films from fluorite-type structure to SBBT structure was suppressed with increasing quantity of bismuth ions. As temperature increased, the phase transformation was improved by excess bismuth ions and decomposition was also avoided. Adding excess bismuth ions caused an increase in the grain size of the prepared films. The value 
of the remanent polarization of thin film was also increased by adding excess bismuth contents. It was found that the ferroelectric characteristics of these films were substantially influenced by the bismuth contents in the films.

\section{References}

[1] K. Amanuma, T. Hase, Y. Miyasaka, Preparation and ferroelectric properties of $\mathrm{SrBi}_{2} \mathrm{Ta}_{2} \mathrm{O}_{9}$ thin films, Appl. Phys. Lett. 66 (1995) 221-223.

[2] C.A. Pazaraujo, J.D. Cuchiaro, M.C. Scott, L.D. Mcmilan, Fatiguefree ferroelectric capacitors with platinum electrodes, Nature 374 (1995) 627-629.

[3] J.F. Scott, F.M. Ross, C.A. De Araujo Paz, M.C. Scott, M. Huffman, Structure and device characteristics of $\mathrm{SrBi}_{2} \mathrm{Ta}_{2} \mathrm{O}_{9}$-based nonvolatile random-access memories, Mater. Res. Soc. Bull. 21 (1996) 33-39.

[4] S.B. Desu, D.P. Vijay, X. Zhang, B.P. He, Orientation growth of $\mathrm{SrBi}_{2} \mathrm{Ta}_{2} \mathrm{O}_{9}$ ferroelectric thin films, Appl. Phys. Lett. 69 (1996) $1719-1721$

[5] T.J. Boyle, C.D. Buchheit, M.A. Rodriguez, H.N. Al-Shareef, B.A. Hernandez, B. Scott, J.W. Ziller, Formation of $\mathrm{SrBi}_{2} \mathrm{Ta}_{2} \mathrm{O}_{9}$. Part I: Synthesis and characterization of a novel sol-gel solution for production of ferroelectric $\mathrm{SrBi}_{2} \mathrm{Ta}_{2} \mathrm{O}_{9}$ thin films, J. Mater. Res. 11 (1996) 2274-2281.

[6] P.C. Joshi, S.O. Ryu, X. Zhang, S.B. Desu, Properties of $\mathrm{SrBi}_{2}$ $\mathrm{Ta}_{2} \mathrm{O}_{9}$ ferroelectric thin films prepared by a modified metalorganic solution deposition technique, Appl. Phys. Lett. 70 (1997) 1080-1082.
[7] K. Kato, C. Zheng, J.M. Finder, S.K. Dey, K. Torii, Sol-gel route to ferroelectric layer-structured perovskite $\mathrm{SrBi}_{2} \mathrm{Ta}_{2} \mathrm{O}_{9}$ and $\mathrm{SrBi}_{2} \mathrm{Nb}_{2} \mathrm{O}_{9}$ thin films, J. Am. Ceram. Soc. 81 (1998) 1869-1875.

[8] C.H. Lu, J.T. Lee, Strontium bismuth tantalate layered ferroelectric ceramics: reaction kinetics and thermal stability, Ceram. Int. 24 (1998) 285-291.

[9] C.H. Lu, Y.C. Chen, Sintering and decomposition of ferroelectric layered perovskites: strontium bismuth tantalate ceramics, J. Eur. Ceram. Soc. 19 (1999) 2909-2915.

[10] C.H. Lu, C.Y. Wen, Phase formation and ferroelectric characteristics of nonfatigue barium bismuth tantalate thin films, J. Appl. Phys. 86 (1999) 6335-6341.

[11] C.H. Lu, C.H. Wu, Preparation, sintering, and ferroelectric properties of layer-structured strontium bismuth titanium oxide ceramics, J. Eur. Ceram. Soc. 22 (2002) 707-714.

[12] Y. Zhu, S.B. Desu, T. Li, S. Ramanathan, $\mathrm{SrBi}_{2} \mathrm{Ta}_{2} \mathrm{O}_{9}$ thin films made by liquid source metal-organic chemical vapor deposition, J. Mater. Res. 12 (1997) 783-792.

[13] P.Y. Chu, R.E. Jones Jr., P. Zurcher, D.J. Taylor, B. Jiang, S.L. Gillespie, Y.T. Lii, Characteristics of spin-on ferroelectric $\mathrm{SrBi}_{2} \mathrm{Ta}_{2} \mathrm{O}_{9}$ thin film capacitors for FERAM application, J. Mater. Res. 11 (1996) 1065-1069

[14] C.H. Lu, B.K. Fang, Secondary phase formation and microstructural development in the interaction between $\mathrm{SrBi}_{2} \mathrm{Ta}_{2} \mathrm{O}_{9}$ films and $\mathrm{Pt} / \mathrm{Ti}$ / $\mathrm{SiO}_{2} / \mathrm{Si}$ substrates, J. Mater. Res. 12 (1997) 2104-2110.

[15] B.H. Kim, D.K. Kang, Characteristics of ferroelectric $\mathrm{Sr}_{0.7} \mathrm{Bi}_{2.1}$ $\mathrm{Ta}_{2.0} \mathrm{O}_{9}$ thin films grown by liquid delivery metal organic chemical vapor deposition process, Thin Solid Films 492 (2005) 140-145.

[16] A.B. Panda, A. Tarafdar, S. Sen, A. Pathak, P. Pramanik, Preparation of nanocrystalline $\mathrm{SrBi}_{2} \mathrm{Ta}_{2} \mathrm{O}_{9}$ powders using sucrosePVA as the polymeric matrix, J. Mater. Sci. 39 (2004) 3739-3744. 